\title{
ОСОБЕННОСТИ МЕТАБОЛИЗМА ОКСИДА
} АЗОТА В ФОРМИРОВАНИИ УРОГЕНИТАЛЬНЫХ РАССТРОЙСТВ У ЖЕНЩИН В ПОСТМЕНОПАУЗЕ И ОБОСНОВАНИЕ ПОДХОДОВ К ИХ УСТРАНЕНИЮ С ИСПОЛЬЗОВАНИЕМ ЭСТРИОЛА

\section{О.В. РОМАЩЕНКО \\ д.мед.н., профессор, главный научный сотрудник отдела андрологии и сексологии Института урологии НАМН Украины \\ С.Н. МЕЛЬНИКОВ}

д.мед.н., профессор, Институт фармакологии и токсикологии

НАМН Украины

А.И. СОЛОВЬЕВ

к.мед.Н., старший

научный сотрудник отдела

сексопатологии и андрологии

Института урологии НАМН

Украины

В.В. БИЛОГОЛОВСКАЯ

к.мед.н., заведующая

отделением ультразвуковой

диагностики Института

урологии НАМН Украины

О.В. КИСЛОВА

Институт фармакологии и токсикологии НАМН Украины

\section{РОЛЬ ОКСИДА АЗОТА}

В РЕГУЛЯЦИИ КРОВОТОКА И ДРУГИХ

БИОЛОГИЧЕСКИХ ФУНКЦИЙ

В НОРМЕ И ПРИ ПАТОЛОГИИ

В начале 80-х годов прошлого столетия группой исследователей в составе Furchgott, Zavadzki и Palmer, Ferrige, Moncada установлена биологическая роль монооксида азота, что стало одновременно и концом, и началом событий мирового масштаба в биологических науках. Концом - потому что поставило точку в длинной, уходящей более чем на 130 лет назад, цепи исследований механизмов терапевтического действия нитроглицерина и других нитровазодилататоров. Начиная с 1867 г., когда Thomas Lauder Brunton впервые использовал амилнитрит для лечения стенокардии, и вплоть до начала 80-х годов прошлого столетия, клеточные механизмы действия терапевтических нитровазодилататоров оставались неизвестными, несмотря на их самое широкое использование в клинике внутренних болезней. Кстати, в истории фрармакологии и медицины это не единственный случай. Аналогичной была судьба другого, не менее известного препарата - аспирина, механизмы действия которого также очень долго оставались неизвестными, что, впрочем, никогда не мешало его огромной популярности среди населения и практикующих врачей. Потребовалось больше века, чтобы стало ясным, что в основе действия амилнитрита и нитроглицерина лежит освобождение молекулы оксида азота (NO) с последующей активацией ею фрермента растворимой гуанилатциклазы, ростом внутриклеточного содержания циклического гуанозинмонофроссрата (цГМФ) и запуском сложного комплекса внутриклеточных процессов, приводящих в итоге к расслаблению гладких мышц сосудов.

Открытие NO как биологического регулятора стало началом развития нового направления В регуляции клеточных функций и коммуникаций. Количество публикаций по фризиологии, фрармакологии, биохимии и патофизиологии увеличилось, и в 1992 г. NO был объявлен молекулой года. Первоначально открытый Furchgott $и$ Zavadzki эндотелиальный релаксирующий фрактор, определяющий, как известно, уровень тонического напряжения гладких мышц сосудов, был затем классифицирован как NO. Позже эта же молекула была идентифицирована как нейропередатчик в центральной и периферической нервной системе, где она принимает участие в регуляции целого ряда важных биологических фрункций, включая процессы обучения и памяти. Механизмы регуляции перистальтики кишечника, эрекции и регуляции выделения гистамина тучными клетками также оказались NO-зависимыми. Затем было установлено, что при воспалении и опухолевом росте натуральные киллеры используют NO для уничтожения бактерий и злокачественно перерожденных клеток. Число известных физиологических и патофизиологических функций, протекающих с участием NO, с каждым годом резко увеличивалось и продолжает расти в настоящее время.

\section{Характеристика и механизмы}

действия оксида азота

NO представляет собой гидрофобный газ с химическими свойствами, делающими его удивительно подходящим на роль внутри- и межклеточного посредника. Он может существовать в виде относительно стабильного, нейтрально заряженного радикала с липофильными свойствами и резко выраженной тенденцией взаимодействовать прежде всего с молекулами, обладающими неспаренным электроном, такими как супероксидный анион, железо и молекулярный кислород. NO может также подвергаться одноэлектронному восстановлению с образованием нитроксильного аниона (NO-) или, потеряв электрон, превращаться в ион нитрозония (NO+ ${ }^{+}$.

Образовавшийся NO представляет собой многофункциональную эфрфекторную молекулу. Основной его мишенью в клетке (иногда даже говорят о внутриклеточном рецепторе $\mathrm{NO}$, что, конечно же, неверно) является растворимая гуанилатциклаза. NO связывается с железом каталитической субъединицы фермента, что приводит к росту активности гуанилатциклазы и накоплению внутри клетки цГМФ. Расслабляющий эффект цГМФ-зависимых протеинкиназ на гладкие мышцы реализуется главным образом посредством контроля концентрации $\mathrm{Ca}^{2+}$ в цитозоле благодаря их влиянию на продукцию инозитол-1,4,5-трифоссрата, активность кальциевых АТФ-аз и активации $\mathrm{Ca}^{2+}$-зависимых 
$\mathrm{K}^{+}$-каналов (Lincoln et al., 1994). Имеются также данные о том, что NO может снижать вход $\mathrm{Ca}^{2+}$ в гладкомышечные клетки через L-тип кальциевых каналов [1].

Относительно недавно в опытах с использованием интактных и химически сканированных сосудистых гладких мышц и фрлюоресцентных методов измерения внутриклеточной концентрации $\mathrm{Ca}^{2+}$ был обнаружен новый, цГМФнезависимый механизм расслабления гладких мышц, обусловленный прямым влиянием NO на сократительные белки гладкомышечных клеток. Было установлено, что NO обладает способностью снижать Са ${ }^{2+-4 у в с т в и т е л ь н о с т ь ~}$ сократительных белков, и этот феномен обусловлен активацией внутриклеточных фоосфатаз, ответственных за десросфорилирование легких цепей миозина [2, 3]. Это открывает перспективы создания принципиально нового класса вазоактивных препаратов, обладающих способностью избирательно модулировать $\mathrm{Ca}^{2+}$-чувствительность сократительных белков и тем самым - уровень сосудистого тонуса.

Важной мишенью для NO в клетке являются белки, содержащие SH-группы [4]. Производное $\mathrm{NO}$, ион нитрозония $\left(\mathrm{NO}^{+}\right)$, легко реагирует c SH-группами, образуя биологически активные S-нитрозосоединения. Очевидно, именно механизм нитрозирования сократительных/регуляторных белков и белков ионных каналов лежит в основе прямого (цГМФ-независимого) и пока еще мало изученного действия NO.

NO может модулировать сосудистую функцию также посредством контроля за экспрессией генов, ответственных за синтез ряда вазоактивных белков, таких как, например, эндотелины, фрактор роста сосудистых клеток и др.

Недавно было доказано [5], что NO принимает участие в процессах мобилизации внутриклеточного кальция посредством стимуляции продукции циклической АДФ-рибозы и последующей активации рианодиновых рецепторов.

\section{Роль оксида азота в развитии \\ патологических процессов}

Параллельно с ростом числа клеточных функций, регулируемых NO, увеличивался и список заболеваний, связанных с нарушением синтеза и/или выделения NO: эссенциальная гипертония, ишемическая болезнь сердца, инфаркт миокарда, бронхиальная астма, первичная легочная гипертензия, невротическая депрессия, импотенция, сахарный диабет - все это далеко не полный перечень патологических процессов, в той или иной степени связанных с изменениями в метаболизме NO. Ему стали приписывать роль основного повреждающего фактора при ишемии мозга, обусловливающего, в частности, нейротоксичность глутамата. В то же время в ряде случаев было показано, что NO может оказывать и отчетливое нейропротекторное действие при ишемии мозга.

Что же касается сосудистой системы в целом, то считается общепринятым, что в диапазоне физиологических концентраций повышение содержания NO всегда коррелирует с увеличением кровоснабжения тканей.

Эта точка зрения и является основной при обсуждении результатов данного фрагмента исследований.

\section{Роль оксида азота в формировании урогенитальных расстройств \\ в менопаузе}

Менопауза, не являясь собственно заболеванием, приводит к нарушению эндокринного равновесия в организме женщины. На фроне десицита половых гормонов, преимущественно эстрогенов, у каждой второй пациентки возникают климактерические нарушения в виде вазомоторных, эмоционально-психических, различных УГР и обменных нарушений.

УГР - это симптомокомплекс вторичных осложнений, связанных с развитием атрофических и дистрофических процессов в эстрогензависимых тканях и структурах нижней трети мочеполового тракта (мочевом пузыре, уретре, влагалище), а также в связочном аппарате малого таза и мышцах тазового дна.

Степень проявления УГР у женщин данной возрастной группы в значительной степени зависит от кровенаполнения сосудов и развития комплекса нейромускулярных эффректов, возникающих со стороны урогенитального тракта [6, 7].

Нормально фрункционирующий эндотелий сосудов характеризуется непрерывным (базальным) выделением NO под воздействием эндотелиальной NO-синтазы. Это необходимо для поддержания фризиологического баланса между вазоконстрикторным и вазодилататорным влиянием на тонус сосудов и, соответственно, на обеспечение адекватного кровоснабжения органов и тканей. Ингибирование эндотелиальной NO-синтазы и уменьшение продукции NO может быть одной из составляющих угнетения дилататорной фрункции эндотелия и нарушения кровоснабжения гениталий и фрормирования УГР [8].

Таким образом, если нарушения в функционировании эндотелия стенок сосудов и обусловленные ими изменения синтеза и/или выделения $\mathrm{NO}$ являются патогенетическим звеном развития УГР в период менопаузы, то это должно определяться параметрами, отражающими динамику обмена NO в гладких мышцах сосудов и эндотелии урогенитального тракта.

Мы поставили перед собой цель изучить частоту и характер проявления УГР у женщин в постменопаузе и обосновать устранение данных нарушений при локальном использовании эстриолсодержащего препарата.

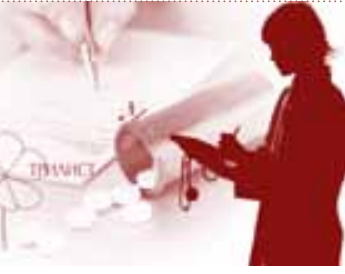

Практически у каждой второй женщины в период менопаузы на фоне эстрогенового десицита формируются УГР, нарушающие качество жизни и требующие адекватной и своевременной коррекции 


\section{МАТЕРИАЛЫ И МЕТОДЫ ИССЛЕДОВАНИЯ}

Было проведено комплексное обследование 440 женщин в возрасте от 42 до 69 лет с длительностью менопаузы от 2 до 23 лет.

В зависимости от выбора и длительности проводимой терапии мы распределили обследованных на 4 группы. Женщинам I, II и IV групп были назначены влагалищные свечи, содержащие эстриол в дозе 0,5 мг (рекомендованная доза согласно инструкции по применению [9]); III была группой сравнения.

Эстриол - эстроген с характерным селективным воздействием на ткани урогенитального тракта [10]. Мы учитывали, что при однократном введении эстриол связывается с ядерным рецептором на непродолжительное время и не вызывает пролиферацию эндометрия, поэтому при его назначении не требуется добавления прогестагенов. Кроме того, для вагинально вводимых низкодозированных эстрогенных препаратов не существует ни абсолютных, ни относительных противопоказаний. В многочисленных исследованиях была продемонстрирована эффективность лечения низкими дозами эстрогенов атрофического вагинита, цистоуретрита и недержания мочи [11]. Как известно, при местном применении эстриола и соблюдении правил, интервалов лечения побочные действия практически отсутствуют [12]. Сочетание различных фрорм эстриолсодержащих препаратов системного и местного применения недопустимо [10].

K тому же терапия эстриолом способствует развитию и восстановлению влагалищного эпителия, а также приводит к восстановлению основных элементов соединительной ткани - коллагена и эластина, чувствительности рецепторов всего урогенитального тракта. Важно отметить, что при локальном использовании эстриола восстанавливается митотическая активность клеток базального и парабазального слоев эпителия слизистых урогенитального тракта, активация эффрерентных компонентов Т-клеточного звена местного иммунитета. Выше представленные механизмы играют также важную роль в устранении и в предупреждении развития вторичной инфрекции у постменопаузальных женщин, потому должны быть учтены при обосновании адекватной терапии УГР, а также сексуальных дисфункций у женщин данной возрастной группы.

В I основной группе 30 обследованным женщинам в течение месяца назначали эстриол сначала по 1 свече ежедневно на протяжении 14 дней, в дальнейшем - по 1 свече 2 раза в неделю (еще 2 нед), и они находились под наблюдением 3 мес.

Bo II основную группу вошли 30 женщин, которым вводили вагинальные свечи эстриола на протяжении 3 мес по схеме: по 1 свече ежедневно в течение 14 дней, в дальнейшем по 1 свече 2 раза в неделю в течение 3 мес, и они находились под наблюдением 3 мес.

В III группу (сравнения) включили 30 женщин, которые пользовались исключительно любрикантом без каких-либо фармакологических добавок в течение месяца (период наблюдения составил $1 \mathrm{mec).}$

В IV группу вошли 350 женщин, которые принимали эстриол В течение месяца по схеме: по 1 свече ежедневно на протяжении 14 дней, в дальнейшем - по 1 свече 2 раза в неделю (период наблюдения составил 1 мес).
Известно, что в результате окисления NO образуются стабильные конечные метаболиты - нитриты и нитраты. Эти соединения являются опосредованными маркерами концентрации NO в биологических средах [13]. Поскольку влагалищный секрет формируется в значительной степени из содержимого жидкой части крови, то содержание в нем метаболитов NO будет отражать концентрацию NO в плазме крови.

Концентрацию нитрит-аниона $\mathrm{NO}^{2-}$ определяли в безбелковых экстрактах содержимого влагалища с помощью реактива Грисса спектрофотометрическим методом [14] на фотометре Screen Master (Италия). Содержание общего белка в пробах определяли по методу Бредфорда [15].

Определение сосудистых реакций осуществлялось путем ультрасонографического исследования с включением метода допплерографии на ультразвуковой диагностической системе XARIO фрирмы TOSHIBA экспертного класса в динамике наблюдения. При использовании цветного допплеровского картирования проводили оценку сосудистой ангиоархитектоники, особенностей паренхиматозного кровотока (его наличие, усиление или отсутствие). Также выполняли импульсную допплерографию с оценкой ее индексов.

Мы использовали следующие показатели допплеровского кровотока: пиковую систолическую скорость (Vps, см/c) и объемную скорость (Vvol, мл/мин).

Определение показателей сосудистого кровотока осуществляли до и после искусственной сексуальной стимуляции. Непосредственно сексуальную стимуляцию проводили путем просмотра пациенткой видео - эротического фильма на протяжении 20-30 мин и нанесением на зону клитора и половых губ возбуждающего любриканта с афродизиаками.

\section{РЕЗУЛЬТАТЫ НАБЛЮДЕНИЙ И ИХ ОБСУЖДЕНИЕ}

С нашей точки зрения, использование представленных выше методологических подходов в настоящем исследовании позволяет провести не только сравнительную оценку эффективности рекомендованной терапии, но и оценить ключевые звенья патогенеза диспареунии и других УГР.

Данные исследования позволили оценить возрастной предел вступления в менопаузу пациенток, провести сравнительный анализ по группам возраста и длительности менопаузы обследованных (табл. 1).

Статистических различий по вышеописанным показателям среди женщин всех групп установлено не было. Средний возраст обследованных женщин составил 54,8 \pm 0,22 года, начало менопаузы 49,0 \pm 1,27 года, ее продолжительность 6,1 \pm 0,17 года.

Частота развития атрофического вагинита с последующей диспареунией на фроне нарушения любрикации установлена у 26,7\% женщин I группы, у 30,0\% - II группы, у 33,3\% - III группы, у 40,0\% - IV группы; а в сочетании с атрофическим цистоуретритом без нарушения контроля мочеиспускания соответственно у 23,3\% - в I группе, у 30,0\% - во II группе, у 26,7\% - в III группе и у $31,4 \%$ - в IV группе.

Таким образом, почти у каждой второй женщины в период менопаузы формировались УГР на фоне эстрогенного дефицита, нарушающие качество жизни и требующие адекватной и своевременной коррекции.

В подтверждение этому мы убедились в наличии возникших изменений при проведении определении уровня 


\section{Показатели \\ Возраст женщины \\ Возраст начала менопаузы \\ Продолжительность мено-} паузы

$\begin{gathered}\text { I группа } \\ \mathbf{n}=\mathbf{3 0}\end{gathered}$
$56,1 \pm 1,18$
$49,5 \pm 1,18$
$6,8 \pm 0,95$

метаболитов NO и ультрасонографического исследования сосудов гениталий.

Проведенные исследования показали, что самые низкие показатели метаболитов NO $(10,9 \pm 1,06$ нмоль/мг белка) наблюдались во II группе женщин с длительностью менопаузы $9,6 \pm 0,95$ года и частотой УГР $60,0 \%$.

На фоне проведения терапии с использованием эстриола уже через неделю была отмечена тенденция к повышению показателей метаболитов NO среди женщин I и II обследованных групп (табл. 2).

Анализ полученных результатов показал, что на фоне применения эстриола уровень метаболитов NO во влагалищном секрете статистически достоверно повышался максимально в 1,5 раза (в среднем с 20,9 до 30,12 нмоль/ мг белка) к 28-му дню наблюдения у женщин I группы и более чем в 3 раза (в среднем с 10,9 до 37,24 нмоль/мг белка) к 21-му дню наблюдения

$\begin{aligned} & \text { II грyпna } \\ & \mathbf{n}=\mathbf{3 0}\end{aligned}$
$58,3 \pm 1,27$
$48,6 \pm 1,27$
$9,6 \pm 0,95$

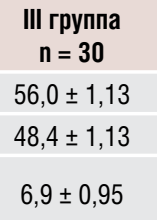

IV группа
$\mathbf{n}=\mathbf{3 5 0}$
$54,3 \pm 0,22$
$49,1 \pm 1,22$
$5,7 \pm 0,2$

Общее число обследованных

$\mathbf{n}=\mathbf{4 4 0}$

$54,8 \pm 0,21$

$49,0 \pm 1,27$

$6,1 \pm 0,17$
ТАБЛИЦА 1

адекватного кровоснабжения органов и тканей. Угнетение эндотелиальной NO-синтазы и уменьшение продукции NO является одной из составляющих угнетения дилататорной функции эндотелия и нарушения кровоснабжения органов при разных патологических состояниях [16].

Если нарушения в функционировании эндотелия сосудов на фоне эстрогенного дефицита и формирующиеся при этом изменения синтеза и продукции NO являются одним из звеньев патогенеза УГР и женских сексуальных дисфункций в период менопаузы, это должно прослеживаться в корреляционной взаимосвязи УГР и параметров, что подтверждают динамику изменения уровня NO в гладких мышцах сосудов и эндотелии урогенитального тракта.

Полученные нами с помощью ультразвуковой допплерографии данные о кровоснаб-
ТАБЛИЦА 1 . И ПРОДОЛЖИТЕЛЬНОСТИ
ИТЛИ ВОЗРАСТА, НАЧАЛА МЕНОПАУЗЫ У ОБСЛЕДОВАННЫХ ЖЕНЩИН

\begin{tabular}{|c|c|c|}
\hline $\begin{array}{c}\text { Группы } \\
\text { наблюдения }\end{array}$ & До лечения & $\mathbf{7}$ дней \\
\hline I $(n=30)$ & $20,91 \pm 2,59$ & $21,86 \pm 3,34$ \\
\hline II $(n=30)$ & $10,9 \pm 1,06$ & $23,16 \pm 2,75$ \\
\hline III $(n=30)$ & $27,77 \pm 2,73$ & - \\
\hline
\end{tabular}

у пациенток II группы. Дальнейшее наблюдение показало, что уровни метаболитов NO у женщин I группы при отсутствии поддерживающей терапии с эстриолом уже через месяц возвращались к исходным данным. В то же время проведение системной терапии с использованием вагинальных глобул с эстриолом по 1 свече 2 раза в месяц сопровождалось сохранением повышенного уровня метаболитов NO в 3,19 раза через 2 мес и в 3,2 раза через 3 мес наблюдения.

Не было выявлено статистически достоверных изменений уровня нитрит-аниона у пациенток III группы, которые использовали нейтральный любрикант, т.е. степень кровенаполнения гениталий у этих пациенток не изменялась.

Как указывалось выше, увеличение выделения NO должно приводить к расширению сосудов и повышению скорости кровотока. Физиологическое фрункционирование сосудов характеризуется стабильным выделением NO под воздействием эндотелиальной NO-синтазы. Это является условием достижения равновесия между вазоконстрикторным и вазодилататорным воздействием на тонус сосудов и, соответственно, на обеспечение жении половых органов подтверждают это предположение - содержание метаболитов NO в динамике клинического использования овестина хорошо коррелирует с результатами наблюдения динамики изменений как Vps, так и Vvol, т.е. соответственно скорости линейного и величины объемного кровотока в клиторе. Так, прирост Vps, в I группе пациенток составил в среднем 1,4 раза, а во II группе - более чем 2,6-2,7 раза (табл. 3). Изменения Vvol в I группе в ходе лечения эстриолом были недостоверными, в то время как для II группы объемная скорость кровотока повысилась более чем в 2 раза (табл. 4), и такое увеличение сохранялось в период наблюдения на фоне использования эстриола (в течение 3 мес).

В случае прекращения использования эстриола эти показатели возвращались до изначальных и подтверждались результатами клинических наблюдений (возобновлялись симптомы УГР, в первую очередь связанные с нарушением кровоснабжения гениталий - снижение любрикации, формирование диспареунии).

\begin{tabular}{|c|c|c|c|}
\hline \multicolumn{4}{|c|}{ Уровень метаболитов NO по срокам наблюдения } \\
\hline $\mathbf{2 1}$ день & $\mathbf{2 8}$ дней & $\mathbf{6 0}$ дней & $\mathbf{9 0}$ дней \\
\hline $25,2 \pm 3,96$ & $30,12 \pm 3,24$ & $23,4 \pm 3,2$ & $20,51 \pm 3,4$ \\
\hline $37,24 \pm 4,35$ & $36,42 \pm 2,48$ & $34,62 \pm 2,36$ & $35,04 \pm 1,95$ \\
\hline- & $26,24 \pm 2,59$ & - & - \\
\hline
\end{tabular}




\begin{tabular}{|c|c|c|c|c|c|c|c|}
\hline \multirow{2}{*}{\multicolumn{2}{|c|}{$\begin{array}{c}\text { Группы } \\
\text { наблюдения }\end{array}$}} & \multicolumn{6}{|c|}{ Показатели максимальной систолической скорости (Vps, cm/ceк) по срокам наблюдения } \\
\hline & & До лечения & 7 дней & 21 день & 28 дней & 60 дней & 90 дней \\
\hline \multirow{3}{*}{$\begin{array}{c}\text { До } \\
\text { стиму- } \\
\text { ляции }\end{array}$} & $I(n=30)$ & $3,3 \pm 0,014$ & $3,94 \pm 0,03$ & $6,42 \pm 0,09$ & $7,85 \pm 0,054$ & $6,75 \pm 0,045$ & $4,74 \pm 0,017$ \\
\hline & $\|(n=30)$ & $2,85 \pm 0,014$ & $3,71 \pm 0,03$ & $6,77 \pm 0,09$ & $8,33 \pm 0,054$ & $7,65 \pm 0,059$ & $7,61 \pm 0,09$ \\
\hline & III $(\mathrm{n}=30)$ & $2,9 \pm 0,014$ & - & - & $2,92 \pm 0,054$ & - & - \\
\hline \multirow{3}{*}{$\begin{array}{l}\text { После } \\
\text { стиму- } \\
\text { ляции }\end{array}$} & $I(n=30)$ & $3,72 \pm 0,022$ & $4,41 \pm 0,03$ & $7,4 \pm 0,09$ & $8,94 \pm 0,054$ & $7,4 \pm 0,045$ & $5,23 \pm 0,017$ \\
\hline & $\|(n=30)$ & $3,28 \pm 0,022$ & $4,34 \pm 0,03$ & $8,02 \pm 0,09$ & $8,99 \pm 0,054$ & $8,46 \pm 0,032$ & $8,32 \pm 0,045$ \\
\hline & III $(n=30)$ & $3,29 \pm 0,022$ & - & - & $3,31 \pm 0,054$ & - & - \\
\hline
\end{tabular}

ТАБЛИЦА 3.

ПОКАЗАТЕЛИ МАКСИМАЛЬНОЙ СИСТОЛИЧЕСКОЙ СКОРОСТИ КРОВОТОКА ПРИ ДОППЛЕРОГРАФИИ СОСУДОВ КЛИТОРА ОБСЛЕДОВАННЫХ ЖЕНЩИН В ДИНАМИКЕ НАБЛЮДЕНИЯ

\section{ВЫВОДы}

Таким образом, проведенные исследования свидетельствуют о том, что применение эстриолсодержащего препарата в виде вагинальных глобулей у женщин в постменопаузе способствует достижению нормализации метаболизма NO в сосудах урогенитального тракта уже к 7-14-му дню использования препарата, кото- рое сопровождается улучшением кровоснабжения половых органов и устранением УГР при его постоянном применении в дальнейшем.

Полученные результаты позволяют констатировать высокую терапевтическую эфффективность эстриолсодержащего препарата в нормализации сосудистой реакции со стороны гениталий, устранении УГР и повышении качества жизни женщины.

\begin{tabular}{|c|c|}
\hline \multicolumn{2}{|c|}{$\begin{array}{c}\text { Группы } \\
\text { наблюдения }\end{array}$} \\
\hline $\begin{array}{c}\text { До } \\
\text { стиму- } \\
\text { ляции }\end{array}$ & I $(\mathrm{n}=30)$ \\
\hline После \\
$\begin{array}{c}\text { стиму- } \\
\text { ляции }\end{array}$ & II $(\mathrm{n}=30)$ \\
\hline & $\mathrm{II}(\mathrm{n}=30)$ \\
\hline
\end{tabular}

Показатели объемной скорости кровотока (Vvol, мл/мин) по срокам наблюдения

\begin{tabular}{|c|c|c|c|c|c|}
\hline До лечения & $\mathbf{7}$ дней & $\mathbf{2 1}$ день & $\mathbf{2 8}$ дней & $\mathbf{6 0}$ дней & $\mathbf{9 0}$ дней \\
\hline $2,58 \pm 0,009$ & $3,45 \pm 0,04$ & $4,09 \pm 0,009$ & $4,10 \pm 0,009$ & $2,9 \pm 0,009$ & $2,72 \pm 0,014$ \\
\hline $2,6 \pm 0,009$ & $3,53 \pm 0,04$ & $4,02 \pm 0,009$ & $4,12 \pm 0,009$ & $4,1 \pm 0,009$ & $4,21 \pm 0,018$ \\
\hline $2,66 \pm 0,014$ & - & - & $2,66 \pm 0,014$ & - & - \\
\hline $3,13 \pm 0,023$ & $4,12 \pm 0,054$ & $5,78 \pm 0,09$ & $6,25 \pm 0,09$ & $4,01 \pm 0,045$ & $3,34 \pm 0,045$ \\
\hline $3,08 \pm 0,023$ & $4,37 \pm 0,054$ & $6,02 \pm 0,09$ & $6,47 \pm 0,09$ & $6,49 \pm 0,054$ & $6,44 \pm 0,045$ \\
\hline $3,03 \pm 0,018$ & - & - & $3,08 \pm 0,018$ & - & - \\
\hline
\end{tabular}

ТАБЛИЦА 4.

ПОКАЗАТЕЛИ ОБЪЕМНОЙ СКОРОСТИ КРОВОТОКА ПРИ ДОППЛЕРОГРАФИИ СОСУДОВ КЛИТОРА ОБСЛЕДОВАННЫХ ЖЕНЩИН В ДИНАМИКЕ НАБЛЮДЕНИЯ

\section{ЛИТЕРАТУРА}

1. Clapp L., Garney A. Modulation of calcium movements by nitroprusside in isolated smooth muscle cells // Pflug. Arch. - 1991. - V. 418. - P. 462-470.

2. Soloviev A., Lehenky V., Zelensky S., Hellstrand P. Nitric oxide relaxes rat tail artery smooth muscle by cyclicGMPindependent decrease in calcium sensitivity of myofilaments // Cell Calcium, 36. - 1996. - P. 165-173.

3. Soloviev A., Hellstrand P., Stefanov A. Nitric oxide but not peroxynitrite relaxes -toxin permeabilized smooth muscle of rat tail artery // J. Vasc. Res. - 1997. - V. 34 (1). - P. 138.

4. Busse R., Fleming I., Schini V. Nitric oxide formation in the vascular wall: regulation and functional implications // In: The role of nitric oxide in physiology and pathophysiology (eds. Koprowski H., Maeda H.). - Springer-Verlag, Berlin-Heidelberg. 1995. - P. 7-18.

5. Lincoln T., Komanavilas P., Cornwell T. Pleotropic regulation of vascular smooth muscle tone by cyclic GMPdependent proteinkinase // Hypertension. - 1994. - V. 23. P. 1141-1147

6. Loewy A.D., McKellar S. Serotonergic projections from the ventral medulla to the intermediolateral cell column in the rat. Brain Res. 1981; 211. - P. 146-152.

7. Wagner G. (1992) Aspects of genital physiology and pathology. Semin Neurol. - 1992: 12. - P. 87-97.

8. Tiritilli A. Nitric oxide (NO), vascular protection factor. Biology, physiological role and biochemistry of NO // Presse Med. - 1998. - № 27 (21). - P. 1061-1065.
9. Инструкция по медицинскому применению препарата Овестин ${ }^{\circledast}$ (эстриол.MSD)

10. Пушкарь Д.Ю., Дьяков В.В., Годунов Б.Н. Овестин в подготовке к трансвагинальным операциям // Урология. - 2002. - № 5. - с. 34-36.

11.Samsiol G. Menopause Review. - 1998. - Vol.3, №1.P. 9-17.

12. Прилепская В.Н., Кулаков В.И., Тизини Г. Лечение урогенитальных нарушений у женщин в постменопаузе препаратом овестин // Акушерство и гинекология. - 1996. - № 32. - с. 37-39.

13 Sun J., Zhang X., Broderick M, Fein H. Measurement of nitric oxide production in biological systems by using Griess reaction assay //

Sensors. - 2003; 3. - P. 276-284.

14. Коцюруба А.В., Семикопна Т.В., Вікторов О.П. Спосіб кількісного визначення нітрит-аніону в біологічній рідині. Патент України UA 31600 A, G 01 N 33/52. - Бюл. № 7-11 від 15.12.2000 p.

15. Bradford M.M. A rapid and sensitive method for the quantitation of microgram quantities of protein utilizing the principleofproteing-dyebinding//Anal.Biochem.-1976;72.P. 248-254.

16. Musicki B., Liu T., Lagoda G., Bivalacqua T., Strong T., Burnett A. Endothelial nitric oxide synthase regulation in female genital tract structures // J. Sex. Med. 2009. - Suppl. 3. - P. 247-53.

MSD-PROMO-Ove-90-05/12. P 